\title{
Hodgkin Lymphoma Transformation of Chronic Lymphocytic Leukemia Under Ibrutinib Therapy: Chance Association or Therapy-related?
}

\author{
SOTIRIOS SACHANAS ${ }^{1}$, GERASSIMOS A. PANGALIS ${ }^{1}$, MARIA MOSCHOGIANNIS ${ }^{1}$, \\ XANTHI YIAKOUMIS ${ }^{1}$, EFSTATHIOS KOULIERIS ${ }^{1}$, PANTELIS TSIRKINIDIS ${ }^{1}$, \\ CHRISTINA KALPADAKIS ${ }^{2}$ and DIMITRA RONTOGIANNI ${ }^{3}$ \\ ${ }^{1}$ Department of Hematology, Athens Medical Center, Psychikon Branch, Athens, Greece; \\ ${ }^{2}$ Department of Hematology, Heraklion University Hospital, University of Crete, Heraklion, Greece; \\ ${ }^{3}$ Department of Anatomic Pathology, Evangelismos General Hospital, University of Athens, Athens, Greece
}

\begin{abstract}
The established treatment algorithms for chronic lymphocytic leukemia (CLL)/small lymphocytic lymphoma (SLL) are currently challenged by novel classes of drugs, with ibrutinib being one of the most effective. Published data suggest that patients with early progression under ibrutinib often emerge as having Richter's transformation (RT) with a rapidly fatal prognosis, mostly developing diffuse large $B$ cell lymphoma (DLBCL). In this respect, it is known that $R T$ to large DLBCL occurs in about $5 \%$ of patients with CLL during the disease course and less frequently to Hodgkin lymphoma $(H L)$. Here, we report a patient with CLL who presented with HL transformation while still receiving therapy with ibrutinib stressing the need for clinical vigilance in any case with persisting or enlarging lymph nodes during treatment with this agent, as prompt modification of therapy is most important.
\end{abstract}

The management of patients with chronic lymphocytic leukemia/small lymphocytic lymphoma (CLL/SLL) is undergoing significant changes. The established treatment algorithms are currently challenged by novel classes of drugs whose mechanisms of action are different from traditional cytotoxic agents and antibodies, with ibrutinib being one of the most effective (1-3).

Ibrutinib, an orally administered inhibitor of Bruton tyrosine kinase (BTK) that antagonizes B-cell receptor

Correspondence to: Sotirios Sachanas, MD, Ph.D., Department of Hematology, Athens Medical Center-Psychikon Branch, 11525, Athens, Greece. Tel: +30 2106974076, Fax: +30 2106984627 email: ssachanas@gmail.com

Key Words: Chronic lymphocytic leukemia, ibrutinib, Richter's syndrome, Hodgkin lymphoma.
(BCR), chemokine, as well as integrin-mediated signaling agent, demonstrated high response rates and prolonged progression-free survival (PFS) in patients with CLL either as first-line therapy or at the relapse setting $(4,5)$. However, published data suggest that patients with early progression under ibrutinib often emerge as having Richter's transformation (RT) with a rapidly fatal prognosis, mostly developing diffuse large B-cell lymphoma (DLBCL) (6). In this respect, it is known that RT to large DLBCL occurs in about $5 \%$ of patients with CLL during the disease course but less frequently to Hodgkin lymphoma (HL) $(7,8)$.

CLL/SLL transformation into $\mathrm{HL}$ is observed in only about $0.5 \%$ of patients and, until now, less than 100 cases have been reported (9-11).

Here, we report a patient with CLL who presented with Hodgkin transformation while still receiving therapy with ibrutinib highlighting the need for histological evaluation of any persisting or enlarging lymph node during treatment with this agent, as histology could reveal potential modification of treatment strategy.

\section{Case Report}

A 69-year-old male was diagnosed in 2009 with CLL stage B Binet stage. The patient was referred to us after a left cervical lymph node biopsy was performed. He was clinically fit, presenting with palpable left cervical and bilateral axillary lymphadenopathy (max diameter of $2 \mathrm{~cm}$ ), as well as palpable splenomegaly $(4 \mathrm{~cm}$ below left costal margin). His blood cell counts showed: White blood cells (WBCs): $16 \times 10^{9} / 1$, lymphocytes: $12.2 \times 10^{9} / 1$, granulocytes: $3.2 \times 10^{9} / 1$, hemoglobin $(\mathrm{Hb}): 13 \mathrm{~g} / \mathrm{dl}$, hematocrit $(\mathrm{Ht}): 42.9 \%$, platelets (PLTs): $142 \times 10^{9} / 1$. No abnormal biochemistry was found and beta-2 microglobulin was within normal limits. Blood smear assessment disclosed a typical picture of CLL, 
while bone marrow examination revealed a diffuse pattern of infiltration. Both blood and bone marrow immunophenotypic analyses were consistent with typical CLL. Meanwhile, lymph node biopsy report was also consistent with CLL. As far as molecular prognostic factors were concerned, the patient was classified as unmutated type, while fluorescence in situ hybridization (FISH) analysis for 17pdel and 11qdel were both negative. The patient was placed on a watch-andwait policy for 2 years until June 2011 when he developed massive splenomegaly, generalized lymphadenopathy and WBC count elevation (WBCs: $94 \times 10^{9} / 1$, lymphocytes: $82 \times 10^{9} / 1$, granulocytes: $8.4 \times 10^{9} / 1, \mathrm{Hb}: 12.2 \mathrm{~g} / \mathrm{dl}, \mathrm{Ht}: 38 \%$, PLTs: $\left.145 \times 10^{9} / 1\right)$. Thus, he received immunochemotherapy with the combination of rituximab with chlorambucil and achieved a partial remission.

Later, in May 2014, at the age of 74, he relapsed showing similar clinical and laboratory characteristics as at initial presentation (WBCs: $100 \times 10^{9} / 1$, lymphocytes: $95 \times 10^{9} / 1$, granulocytes: $4.5 \times 10^{9} / 1$, Hb: $12 \mathrm{~g} / \mathrm{dl}$, Ht: $36 \%$, PLTs: $\left.180 \times 10^{9} / 1\right)$. He was treated with a combination of rituximab, fludarabine and cyclophosphamide (FCR) receiving six cycles and he, again, achieved good partial response (PR) lasting until August 2016 when he relapsed again with generalized lymphadenopathy, splenomegaly and a WBC count of $40 \times 10^{9} / 1$. Before new treatment initiation, FISH analysis for 17pdel was still negative. Since ibrutinib was commercially available, the patient was started on this agent at the standard dose of 420 $\mathrm{mg}$ /day in early September 2016. Gradually, all palpable lymph nodes decreased other than a right submandibular lymph node, which remained stable with a max diameter of $3 \mathrm{~cm}$ (Figure 1). Initially, this finding was considered as a reactive lymph node due to co-existence of herpes simplex lip infection and, therefore, acyclovir and antibiotics were administered without, however, any improvement.

In December 2016, after being on ibrutinib for four months, it was decided to perform a biopsy of this submandibular lymph node. The results showed HL with typical ReedSternberg, Hodgkin cells both CD30- and CD15-positive, mixed with lymphoid cells with immunophenotypic features of CLL. Antibody to LMP-1 antigen of Epstein-Barr virus (EBV) was also positive in these cells (Figure 1).

As a consequence, the patient was diagnosed with HL transformation of CLL and, thus, ibrutinib was discontinued and started receiving the adriamycin, bleomycin, vinblastine, dacarbazine (ABVD) regimen that, after 2 cycles, shows a promising response.

\section{Discussion}

CLL is characterized by clinical and biological heterogeneity. The term Richter's syndrome (RS) or RT represents the development of lymphoma in a patient with CLL. Approximately 2-10\% of patients with CLL will develop RS during the course of their disease and, in $85-90 \%$ of cases, histopathology shows aggressive DLBCL. Less frequently, CLL may progress into HL, now termed Hodgkin's variant (HV) of RS, which comprises only $10-15 \%$ of all RS cases (7-11). Two types of Hodgkin transformation of CLL/SLL have been described. Type 1 is characterized by HodgkinReed Sternberg (H-RS) cells scattered in a background of CLL cells, which was the case of the patient described herein, while, in the type 2 transformation, H-RS cells are present in a typical polymorphous, inflammatory background that is separate from CLL (9-11).

The largest series of Hodgkin transformation in CLL/SLL was reported from M. D. Anderson Cancer Center (MDACC) where, among 4,121 patients, only 18 had (0.4\%) transformed to HL (9).

Ibrutinib, an orally administered inhibitor of BTK that antagonizes BCR, has become a new standard-of-care in CLL, especially for patients with unfavorable genetic characteristics, such as $17 \mathrm{p}$ deletion (5). While ibrutinib therapy induces high response rates improving PFS even in high-risk CLL patients, one of the reasons for ibrutinib discontinuation is disease progression. Recently, it has been reported that, among 31 patients discontinuing therapy due to disease progression, in four clinical trials, 13 progressed with CLL and 18 with RT. Among patients with RT, 78\% developed DLBCL, while one developed HL, one plasmablastic lymphoma, one composite Band T-cell lymphoma and one peripheral T-cell lymphoma (6).

The patient of the current case presented with HL transformation 4 months after ibrutinib initiation, which is in line with published data that RT tends to occur early in the course of treatment with an estimated cumulative incidence of RT of $4.5 \%$ at 12 months (6). Maddocks et al. showed that parameters, such as increased number of prior therapies, BCL6 and MYC abnormalities, presence of $\operatorname{del}(17 \mathrm{p})$ and complex karyotype, were all significantly associated with a higher risk of progression- and diseaserelated discontinuation of ibrutinib, while, in multivariable analysis, presence of BCL6 abnormalities $(p=0.012)$ and complex karyotype $(p=0.007)$ remained independent risk factors (6). An increased baseline lactate dehydrogenase (LDH) also appeared to be associated with development of RT (6). The patient described here had received two prior lines of treatment and, from the available data, it is apparent that he had normal baseline LDH levels without TP53 abnormalities. It is noteworthy that, at the time of diagnosis of CLL transformation, the patient was clinically fit without any B-symptoms, in accordance with the observation derived from the Israeli CLL Study Group that clinical presentation during RT into HL is not as "stormy" as RT to DLBCL (12).

Another interesting finding relates to the fact that EBV was positive in the RT cells of the patient, thus supporting the hypothesis of a possible role of EBV infection in the etiology of RS-Hodgkin's variant of CLL $(9,12-13)$. The precise role 


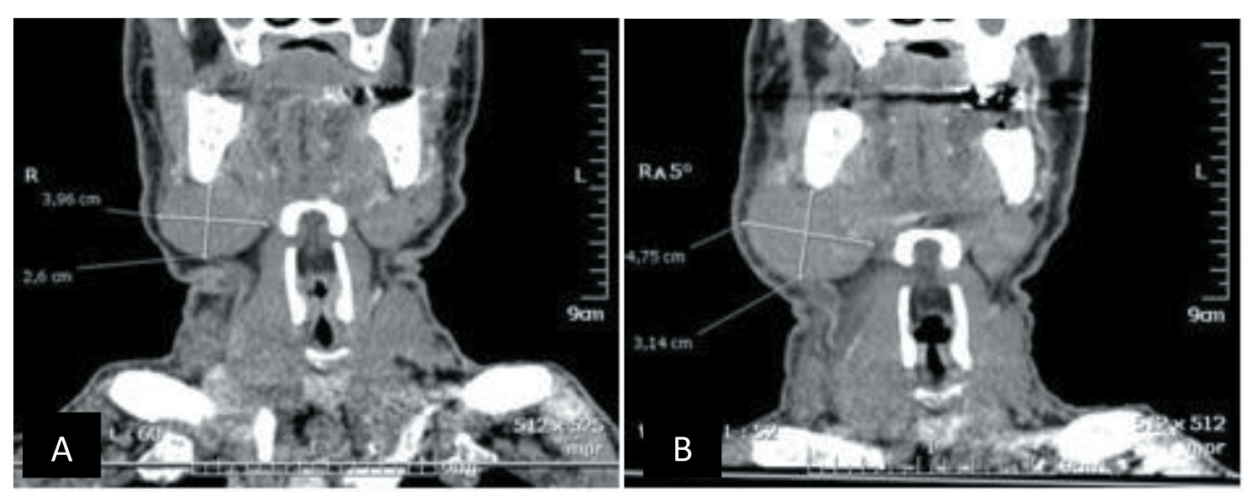

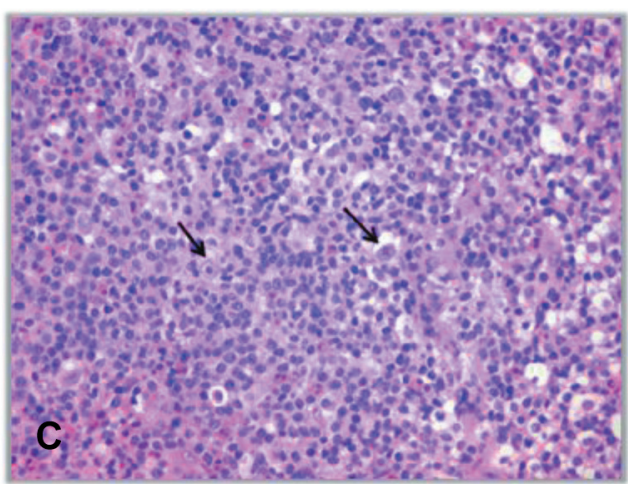

HEX400

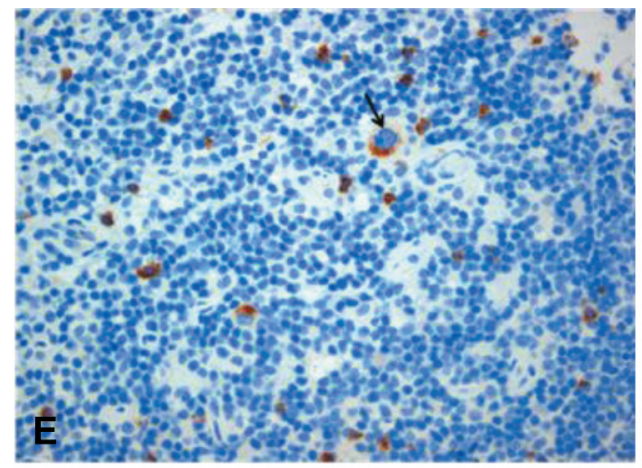

$\operatorname{CD} 15 \times 400$

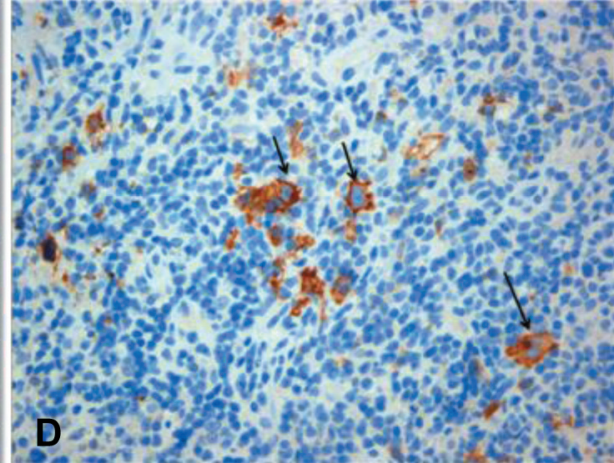

$\operatorname{CD} 30 \times 400$

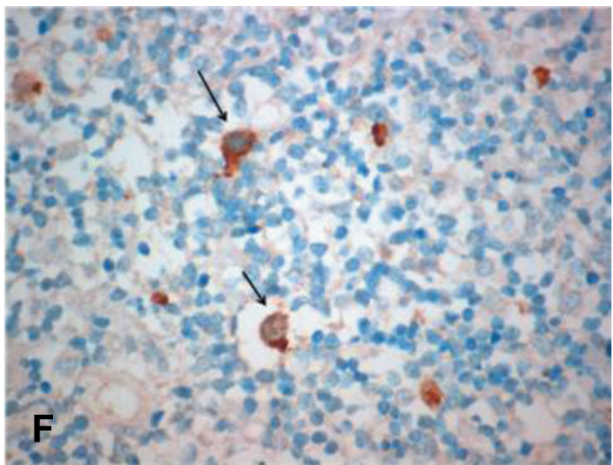

IMP.1(EBV) $\times 600$

Figure 1. Computerized tomography and histology of submandibular lymph node. A, B: Computerized tomography of submandibular lymph node before ibrutinib initiation and during ibrutinib therapy, respectively, discloses a slight increase at both transverse and sagittal lymph node diameters. $C, D$, E, F: Immunological slides show the presence of Hodgkin cells (arrows) scattered in a background of chronic lymphocytic leukemia (CLL) cells (C), which are both CD30- and CD15-positive (arrows D, E), while antibody to LMP-1 antigen of Epstein-Barr virus was also positive (arrows) (F).

of EBV infection still needs to be defined in RS and in HVRS in particular. However, the biological rationale for this association may, indeed, relate to the degree of pre-existing immunosuppression in CLL, which may be enhanced by the use of agents with proven immunosuppressive effect(s) like fludarabine or other agents with yet unknown long-term immunological consequences due to BTK inhibition, such as ibrutinib.
Treatment of patients with Hodgkin RT in CLL/SLL is challenging. Our patient was placed on ABVD therapy with an initial response confirming the results of the MDACC study that showed that HL-type multiagent chemotherapy, such as ABVD, was effective (9). However, the same study also reported that the majority of patients eventually relapsed after a short period of time, thus emphasizing the need for a more specific treatment approach, considering the possible 
role of EBV in the pathogenesis of the disease as a potential therapeutic target (9).

To our knowledge, this is only the second case of CLL with RT into HL in a patient receiving ongoing ibrutinib therapy (6) highlighting the need for clinical awareness in cases of CLL with suspicious lymph node enlargement during ibrutinib therapy, as the prompt recognition of this extremely rare entity is of paramount importance in adapting the suitable therapy.

\section{References}

1 Cramer P, Hallek M and Eichhorst B: State-of-the-Art treatment and novel agents in chronic lymphocytic leukemia. Oncol Res Treat 39: 25-32, 2016.

2 Cramer P, Langerbeins P, Eichhorst B and Hallek M: Advances in first-line treatment of chronic lymphocytic leukemia: Current recommendations on management and first-line treatment by the German CLL Study Group (GCLLSG). Eur J Haematol 96: 9$18,2016$.

3 Morabito F, Gentile M, Seymour JF and Polliack A: Ibrutinib, idelalisib and obinutuzumab for the treatment of patients with chronic lymphocytic leukemia: Three new arrows aiming at the target. Leuk Lymphoma 56: 3250-3256, 2015.

4 Burger JA, Tedeschi A, Barr PM, Robak T, Owen C, Ghia P, Bairey O, Hillmen P, Bartlett NL, Li J, Simpson D, Grosicki S, Devereux S, McCarthy H, Coutre S, Quach H, Gaidano G, Maslyak Z, Stevens DA, Janssens A, Offner F, Mayer J, O'Dwyer M, Hellmann A, Schuh A, Siddiqi T, Polliack A, Tam CS, Suri D, Cheng M, Clow F, Styles L, James DF and Kipps TJ; RESONATE-2 Investigators: Ibrutinib as initial therapy for patients with chronic lymphocytic leukemia. N Engl J Med 373: 2425-2437, 2015.

5 O'Brien S, Jones JA, Coutre SE, Mato AR4, Hillmen P5, Tam C6, Österborg A, Siddiqi T, Thirman MJ, Furman RR, Ilhan O, Keating MJ, Call TG, Brown JR, Stevens-Brogan M, Li Y, Clow F, James DF, Chu AD, Hallek M and Stilgenbauer S: Ibrutinib for patients with relapsed or refractory chronic lymphocytic leukaemia with $17 \mathrm{p}$ deletion (RESONATE-17): A phase 2, openlabel, multicentre study. Lancet Oncol 17: 1409-1418, 2016.
6 Maddocks KJ, Ruppert AS, Lozanski G, Maddocks KJ, Ruppert AS, Lozanski G, Heerema NA, Zhao W, Abruzzo L, Lozanski A, Davis M, Gordon A, Smith LL, Mantel R, Jones JA, Flynn JM, Jaglowski SM, Andritsos LA, Awan F, Blum KA, Grever MR, Johnson AJ, Byrd JC and Woyach JA: Etiology of ibrutinib discontinuation and outcomes in chronic lymphocytic leukemia patients. JAMA Oncol 1: 80-87, 2015.

7 Pangalis GA, Vassilakopoulos TP, Dimopoulou MN, Siakantaris MP, Kontopidou FN and Angelopoulou MK. B-Chronic lymphocytic leukemia: Practical aspects. Hematol Oncol 20: 103-146, 2002.

8 Tsimberidou AM, Keating MJ and Wierda WG: Richter's transformation in chronic lymphocytic leukemia. Curr Hematol Malig Rep 2: 265-2671, 2007.

9 Tsimberidou AM, O'Brien S, Kantarjian HM, Koller C, Hagemeister FB, Fayad L, Lerner S, Bueso-Ramos CE and Keating MJ. Hodgkin transformation of chronic lymphocytic leukemia: The M.D. Anderson Cancer Center experience. Cancer 107: 1294-1302, 2006.

10 Janjetovic S, Bernd HW, Bokemeyer C and Fiedler W: Hodgkin's lymphoma as a rare variant of Richter's transformation in chronic lymphocytic leukemia: A case report and review of the literature. Mol Clin Oncol 4: 390-392, 2016.

11 Jamroziak K, Tadmor T, Robak T and Polliack A: Richter syndrome in chronic lymphocytic leukemia: Updates on biology, clinical features and therapy. Leuk Lymphoma 56: 1949-1958, 2015.

12 Tadmor T, Shvidel L, Goldschmidt N, Ruchlemer R, Fineman R, Bairey O, Rahimi-Levene N, Herishanu Y, Yuklea M, Arad A, Aviv A and Polliack A: Hodgkin's variant of Richter transformation in chronic lymphocytic leukemia: A retrospective study from the Israeli CLL study group. Anticancer Res 34: 785-790, 2014.

13 Xiao W, Chen WW, Sorbara L, Davies-Hill T, Pittaluga S, Raffeld M and Jaffe ES: Hodgkin lymphoma variant of Richter transformation: Morphology, Epstein-Barr virus status, clonality, and survival analysis-with comparison to Hodgkin-like lesion. Hum Pathol 55: 108-116, 2016.

Received March 31, 2017

Revised April 18, 2017

Accepted April 19, 2017 